\title{
Effect of 8-Week Aquatic Training and Resistance Training on Plasma NT-4 Levels and NT-4 Expression in Peripheral Blood Mononuclear Cells in Women with Multiple Sclerosis
}

\author{
Asra Askari (PhD candidate) \\ Department of Sport Physiology, \\ Faculty of Physical Education and \\ Sport Sciences, Ferdowsi University of \\ Mashhad, Mashhad, Iran \\ Amir Rashid Lamir (PhD) \\ Department of Sport Physiology, \\ Faculty of Physical Education and \\ Sport Sciences, Ferdowsi University of \\ Mashhad, Mashhad, Iran \\ Nahid Bijeh (PhD) \\ Department of Sport Physiology, \\ Faculty of Physical Education and \\ Sport Sciences, Ferdowsi University of \\ Mashhad, Mashhad, Iran \\ Majid Momeni Moghadam (PhD) \\ Department of Biology, Faculty of \\ Basic Sciences, Hakim Sabzevari \\ University, Sabzevar, Iran \\ Corresponding author: Amir Rashid \\ Lamir \\ E-mail: rashidlamir@um.ac.ir \\ Tel: +989151514174 \\ Address: Faculty of Physical \\ Education and Sport Sciences \\ Ferdowsi University of Mashhad, \\ Mashhad, Iran \\ Received : 08 Oct 2017 \\ Revised: 01 Nov 2017 \\ Accepted: 09 Nov 2017
}

\section{ABSTRACT}

Background and Objectives: The present study aimed to investigate effects of eight weeks of aquatic exercise and resistance training on plasma neurotrophin-4 (NT-4) levels and NT-4 expression in peripheral blood mononuclear cells (PBMCs) of women with multiple sclerosis (NS).

Methods: Thirty women with MS were randomly assigned to a resistance-training group, an aquatic exercise group and a control group. After separating plasma and PBMCS from blood samples, level of plasma NT-4 and NT-4 expression was measured after eight weeks of exercise via ELISA and Real-time PCR, respectively.

Results: The level of plasma NT-4 and NT-4 expression increased significantly following eight weeks of aquatic training and resistance training.

Conclusion: Based on the results of the present study, both resistance training and aquatic exercise can increase the level of plasma NT-4 and NT-4 expression in female MS patients. It can be concluded that such trainings could have protective and positive effects on the nervous system of MS patients.

Keywords: Exercise, Multiple Sclerosis, Neurotrophic Factors, Women. 


\section{INTRODUCTION}

Multiple sclerosis (MS) is one of the most prevalent neurologic diseases, causing demyelination and axonal damage (1). This disease affects young people, especially women. More than 2.5 million people around the world suffer from MS and its prevalence is increasing (2). Most cases can live with relapsing-remitting MS for many years, but may develop secondary progressive MS. Although the main cause of MS remains unknown, role of the immune system in the spread of the disease has been well established $(3,4)$. Most scientists believe that factors including the person's immunity, genetic inheritance, age, geographical location and previous viral infection can affect the risk of developing MS $(5,6)$. In addition, it has been suggested that changes in neurotrophic factors could be involved in pathogenesis of neurodegenerative disorders, such as MS (7). Neurotrophins are a family of proteins that are involved in the survival, development and function of neurons (8). Neurotrophin-4 (NT4 ) is mainly expressed by motor neurons in the ventral horn of the spinal cord, and plays an important role in the protection and survival of motor neurons (9). These neurotrophins have been studied as biomarkers for MS (10). It is thought that they may be involved in the effects of physical exercise on the central nervous system (CNS) and body function (11). Nowadays, patients with refractory MS require special attention due to their psychological and emotional state and the high costs treatment. Secondary prevention (treatment) and tertiary prevention (rehabilitation) are necessary for improving the overall condition of MS patients (12). The present study aimed to investigate effects of 8-week aquatic exercise and resistance training on plasma level of NT-4 and NT-4 expression in peripheral blood mononuclear cells (PBMC) of women with MS.

\section{MATERIAL AND METHODS}

This quasi-experimental study was performed on 30 female MS patients from Mashhad MS Association (Iran) who were purposely selected based on self-conscious consent. The study was approved by the ethics committee of Ferdowsi University of Mashhad (No. 21248), and in accordance with the declaration of Helsinki (1964).

\section{Inclusion Criteria}

1) Subjects should did not taken part in any exercise or physical activity in the last three months prior to the study.

2) Subject did not have acute cognitive limitation.

3) No severe nervous symptom within four weeks prior to the study.

4) No history of orthopedic, cardiorespiratory and metabolic disorders, and consumption of any medication except for Avonex® ${ }^{\circledR}$, Rebif $\AA$, Betaferon ${ }^{\circledR}$ and CinnoVex.

5) EDSS scale of 2-4 (13).

The participants were randomly assigned to three equal groups consisting of an aquatic exercise group, a resistance-training group and a control group. The exercise groups engaged in exercise training three sessions a week for eight weeks, while the control group did not perform any exercise.

It should be noted that diet of the participants was not monitored as it was beyond the scope of the current study.

The aquatic exercise program was performed three sessions a week for eight weeks. The participants in the aquatic exercise group exercised for 30 minutes in each session. Each session included 5-minute warm-up, 20minute aerobic exercise, and 5-minute cool down. During warm-up and cool down, aerobic exercise was performed smoothly with low intensity. The structure and duration of each training session were based on the instructions prescribed for MS patients (14).

This training was performed three sessions a week for eight weeks at $40-70 \%$ of onerepetition maximum. The training session started with a five-minute warm-up, followed by resistance training for 30-45 minutes. In order to carry out the resistance-training program, the following devices were used: leg press, H-machine, chest press and leg extension. The break between the sets and workouts was 60-90 seconds and two minutes, respectively. The $1 \mathrm{RM}$ test was carried out in the beginning and at the end of the fourth week, using the Brzycki equation (15). The intensity of training and frequency of repetitions and sets are shown in Table 1. A 10 - to 15-minute cool down period was instructed at the end of each training session (16). 
Fasting blood samples were collected 48 hours before the first training session and 48 hours after the last training session. The blood samples were preserved in tubes with anticoagulant (EDTA). After separating plasma and PBMCs (17), each sample was preserved in a freezer at $-70{ }^{\circ} \mathrm{C}$ until the time of testing. After purifying mRNA from PBMCs, cDNA was synthesized using Oligo (dT) primers and relevant kits (Fermentas, Germany). Expression of the NT-4 gene was assessed by Real-time PCR using BIORAD (C1000) thermal cycler in 96-well plates.

Table 2 shows the sequences of NT-4 (18) primers and $\beta$-actin (17) used in the experiment. Plasma level of NT-4 was measured by ELISA using commercial kits (Chongqing Biospes Co., Ltd).

\section{Real-time PCR}

The PCR experiment was performed according to the following instructions: initial denaturation at $95{ }^{\circ} \mathrm{C}$ for five minutes (one cycle), denaturation at $95{ }^{\circ} \mathrm{C}$ for 10 seconds, primer annealing and extension at $60{ }^{\circ} \mathrm{C}$ for 30 seconds, and melting curve analysis at 55-95 ${ }^{\circ} \mathrm{C}$ for six and half minutes and 45 cycles (19).

The comparative CT method was used for measuring the copies of the target and reference genes (20). Data were analyzed with descriptive and inferential statistics in SPSS (version 18). After assessing the normality of data distribution by using Shapiro-Wilk test, level of plasma NT-4 and NT-4 expression were analyzed using ANOVA and pairedsamples t-test, respectively. All statistical analyses were performed at significance level of 0.05 .

Table 1- Details of the weekly resistance training program used in the study

\begin{tabular}{|c|c|c|c|c|c|c|c|c|c|}
\hline Week & First & Second & Third & Fourth & $\begin{array}{l}\text { IRM } \\
\text { Test }\end{array}$ & Fifth & Sixth & Seventh & Eighth \\
\hline $\begin{array}{c}\text { Intensity of 1RM } \\
(\%)\end{array}$ & $40-45$ & $40-45$ & $50-60$ & $60-65$ & & $60-70$ & $50-60$ & $60-70$ & $65-70$ \\
\hline $\begin{array}{l}\text { Number of sets } \\
\text { Number of } \\
\text { repetitions }\end{array}$ & $\begin{array}{c}2 \\
10-12\end{array}$ & $\begin{array}{c}3 \\
12-14\end{array}$ & $\begin{array}{c}2 \\
10-12\end{array}$ & $\begin{array}{c}3 \\
10-12\end{array}$ & & $\begin{array}{c}3 \\
10-12\end{array}$ & $\begin{array}{c}3 \\
10-12\end{array}$ & $\begin{array}{c}3 \\
10-12\end{array}$ & $\begin{array}{c}3 \\
10-12\end{array}$ \\
\hline
\end{tabular}

Table 2- Sequences of the primers used in the study

\begin{tabular}{ccc}
\hline Gene & Type & Primer sequence \\
\hline$N T-4$ & Forward & AGCGAAACTGCACCAGCGAG \\
& Reverse & CACCTTCCTCAGCGTTATCA \\
$\beta$-actin & Forward & TCCCTGGAGAAGAGCTACG \\
& Reverse & GTAGTTTCGTGGATGCCACA \\
\hline
\end{tabular}

\section{RESULTS}

Mean age and mean weight of the participants was $35.05 \pm 4.7$ years and $60.70 \pm 4.46 \mathrm{Kg}$, respectively. Mean plasma NT-4 levels increased significantly in both training groups after the exercise program. Moreover, NT-4 expression increased significantly in both training groups (Table 3 ).

Results of the covariance analysis showed a significant increase in plasma levels of NT-4 in all study groups (Table 4). Results of the ANOVA showed a significant increase in expression of NT-4 in all study groups. There was a significant difference in the plasma NT4 levels between the aquatic training group and the resistance-training group.

Table 3- Level of plasma NT-4 and NT-4 expression in all study groups before and after the exercise training

\begin{tabular}{|c|c|c|c|c|c|}
\hline \multirow[t]{2}{*}{ Variable } & \multirow[t]{2}{*}{ Group } & \multirow[t]{2}{*}{ Pre-test $($ Mean \pm SD) } & \multirow[t]{2}{*}{ Post-test $($ Mean \pm SD) } & \multicolumn{2}{|c|}{ T-dependent } \\
\hline & & & & $\mathbf{T}$ & $\mathbf{P}$ \\
\hline \multirow[t]{3}{*}{ NT-4 (pg/ml) } & Aquatic Exercise & $355.23 \pm 1412.44$ & $413.33 \pm 1997.44$ & -8.493 & $0.001 *$ \\
\hline & Resistance training & $329.95 \pm 1631.30$ & $390.66 \pm 2267.40$ & -14.815 & $0.001 *$ \\
\hline & Control & $419.12 \pm 1470.42$ & $363.40 \pm 1408.28$ & 1.620 & 0.15 \\
\hline \multirow[t]{3}{*}{ NT-4/ק-actin ratio } & Aquatic exercise & 1.00 & $0.53 \pm 1.73$ & -4.128 & $0.003^{*}$ \\
\hline & Resistance training & 1.00 & $0.67 \pm 2.48$ & -7.00 & $0.001 *$ \\
\hline & Control & 1.00 & $0.003 \pm 1.001$ & -1.312 & 0.23 \\
\hline
\end{tabular}


Table 4- Between-group variations of plasma NT-4 and NT-4 expression levels

\begin{tabular}{cccc}
\hline Variable & DF & F & P \\
\hline NT-4(pg/ml) & 2 & 44.93 & 0.001 \\
NT-4/B-actin & 2 & 16.71 & 0.001 \\
\hline
\end{tabular}

\section{DISCUSSION}

We found a significant increase in plasma NT-4 and NT-4 expression in PBMCs in the aquatic and resistance training groups compared with the control group. In addition, within-group analysis showed a significant increase in the level of plasma NT-4 and NT-4 expression in PBMCs in each exercise group. Most studies on neurodegenerative disorders have focused on growth and repair of damaged tissues by triggering the stem cell-based regeneration of normal tissues via exercise or medication. In this regard, exercise seems to have useful effects on the brain by affecting the level of neurotrophins (21). Some studies have investigated the effect of exercise on some growth factors using animal models (22, 23). Neuron of healthy adults act as major sources of neurotrophins, and neurotrophic factors derived from immune cells have minor effects, given the fact that only immunologically active cells can trespass the blood-brain barrier. However, dynamic interactions have been observed between neurons and the immune system of MS patients. In other words, neurotrophins expressed in the immune cells are considered as biomarkers for MS (24).

Neurotrophins function in the nervous system is via low- and high-affinity neurotrophin surface receptors (25). Clinical studies have revealed that concentration of NT-4 in PBMCs is significantly correlated with brain atrophy in MS patients (9). Furthermore, neurotrophic growth factors play an important role in regulation of myelin production in oligodendrocytes and Schwann cells in vitro. For instance, NT-3 can participate in myelination after injury $(26,27)$.

Based on our results, both resistance training and aquatic training increased level of plasma NT-4 and NT-4 expression in PBMCs. This indicates the potential role of exercise training in myelination and improvement of MS. Resistance training increases muscle mass and strength through repetitive and regular training with weights (21). This type of training can improve endurance and balance in MS patients (21). Resistance training also affects neurotrophic factors in muscles and their receptors (28). However, the mechanisms through which physical activity can influence the level of NT-4 in MS patients are not clear. Gomez-Pinnilla et al. reported that NT-3 expression increased in rats after continuous running for one day and treadmill running for five days, which is in line with our findings (29). However, in study of Ying et al., three days of training had no effect on NT-3 expression and TrkC level in soleus muscles (30). In study of Eslami et al., one session of resistance training had no effect on expression of NT-3 but increased TrkC expression in soleus muscles of rats, which is inconsistent with the results of the present study (31).

Considering the common symptoms of MS such as decreased walking ability, fatigue, muscle weakness and imbalance (32), aquatic training can be suggested to MS patients to relieve pressure from the muscles and help the body perform regular movements (33). To date, limited number of studies on the effects of aquatic trainings on neurotrophic factors in MS patients has investigated the effects of such trainings on quality of life and fatigue $(34,35)$. Our study is the first to report that overexpression of NT-4 after aquatic training in women with MS can have positive effects as a non-drug treatment strategy.

Previous studies have reported that regulation of NT-4 expression (especially in skeletal muscles) differs from other neurotrophins (36). Although the results of the present study showed an increase in NT-4 expression after exercise training, study of Walker and Schon reported no difference in NT-4 expression between sedentary men and cyclists who performed aerobic exercise (37). Considering the conflicting results of such studies, further studies are required to elicit the exact effects of exercise training on neurotrophic factors. 


\section{CONCLUSION}

Based on the results of the present study, both resistance training and aquatic training can increase NT-4 plasma levels and NT-4 expression in female MS patients. It can be concluded that such trainings could have protective and positive effects on the nervous system of MS patients.

\section{REFERENCES}

1.Makvandi Z, Sadeghi Haj M, Sarbrofzad A, Majidi Nasab N. The relationship between HH V-6 and HHV7 viruses with multiple sclerosis disease in Khuzestan province. $12^{\text {th }}$ Iranian congress, Sari. 2015.

2.Nouri M. An Investigation and Comparison of the Increasing Scale of MS Exposure in Different Countries of the World. 12 $2^{\text {th }}$ Congress of ms of Iran, Sari. 2015.

3.Ksiazek-Winiarek D, Szpakowski P, Glabinski A. Neural Plasticity in Multiple Sclerosis: The Functional and Molecular Background. Hindawi Publishing Corporation. 2015.

4.Azadvari M, Kazemi Sh, Emami S. The Need for Urinary Problems in Women Affected by Multiple Sclerosis and its Treatment. 12th Congress of ms of Iran, Sari. 2015.

5.balouchy R, ghiasi A, naderi E, sodoghi $\mathrm{H}$. The survey of Cawthorne and Cooksey exercise on the quality of life, balance and fatigue in patients with multiple sclerosis. sjimu. 2014; 21(7): 43-53.

6.Reiisi S, Shahi H, Sanati MH. Gene Therapy in Multiple Sclerosis (MS). Genetics in the Third Millennium. 2014; 12(4): 3824- 3832.

7.Azoulay D, Urshansky N, Karni A. Low and dysregulated BDNF secretion from immune cells of $M S$ patients is related to retuced neuroprotection. Journal of Neuroimmunology. 2008; 195(1-2): 186-193. doi: 10.1016/j.jneuroim.2008.01.010.

8.Zangi M, Ofoghi H. Nerve growth factor, clinical applications and production of the recombinant protein. JQUMS. 2017; 20(6): 53-70.

9.Khan N, Smith MT. Neurotrophins and Neuropathic Pain: Role in Pathobiology. Molecules. 2015; 20 : 10657-88. doi: 10.3390/molecules200610657.

10.khalil nejhad A, zahed nasab $\mathrm{H}$, khodabande lo $\mathrm{H}$, mahmodian E, azar abdar T, balood M, et al . Diagnostic Biomarkers in Multiple Sclerosis. sjimu. 2014; 21(7): 288-311.

11.Motl R, Pilutti L. The benefits of exercise training in multiple sclerosis. Neurology. 2012; 8(9): 487-497. doi: 10.1038/nrneurol.2012.136.

12.Nazari Telaki Z, Abedini M, Nazari Telaki M. A recent study on the demographic characteristics of the clinical course of the disease, the trend in MS patients in Mazandaran and Kerman. $12^{\text {th }}$ Iranian congress, Sari. 2015.

13. Moradi M, Kordi MR, Sahraian MA, Mehri K, Hosseini SH. The Effect of Eight-Week Resistance Training on Muscular Strength and Balance in Men with Multiple Sclerosis. 2012; 4(1): 5-22.

\section{ACKNOWLEDGEMENTS}

We would like to thank all participants in the study.

\section{CONFLICT OF INTEREST}

The authors declare that there is no conflict of interest.

14.Mohammadi G, Naghibzade A, Rezaee Namjoo F, Rashidlamir A. the effects of massage and aqua training on interleukin-6 levels of multiple sclerosis patients. Edizioni Minerva Medica.2016; 175(10): 408-12.

15. Ferguson B. ACSM's guidelines for exercise testing and prescription. J Can Chiropr Assoc. 2014; 58(3): 328. 16. Whitem LJ, Dressendorfer RH. Exercise and multiple sclerosis. Sports Med. 2004; 34(15): 1077-1100.

17. Rashidlamir A. Investigation of the Effect of Aerobic and Resistance Exercises on Peripheral Blood Mononuclear Cells ABCG1 Gene Expression in Female Athletes. JSSU. 2012; 20(1): 1-9.

18.Labouyrie E, Dubus P, Groppi A, Xavier Mahon F, Ferrer J, Parrens M, et al. Expression of Neurotrophins and their Receptors in Human Bone Marrow. American Journal of Pathology. 1999; 154(2): 405-415.

19.Ghanbari-Niaki A, Ghanbari-Abarghooi S, Rahbarizadeh F, Zare-Kookandeh N, Gholizadeh M, Roudbari F, et al. Heart ABCAl and PPAR- $\alpha$ Genes Expression Responses in Male rats: Effects of High Intensity Treadmill Running Training and Aqueous Extraction of Black Crataegus-Pentaegyna. Res Cardiovascular Med. 2013; 1(5): 153-159. doi: 10.5812 /cardiovascmed.13892.

20.Livak KJ, Schmittgen TD. Analysis of relative gene expression data using real-time quantitative $P C R$ and the 2(-Delta DeltaC(T)) Method. Methods. 2001; 25(4): 402-408. DOI:10.1006/meth.2001.1262.

21.Mojtahedi S, Shabkhiz F, Akbarnejad A, Salehian O. Effect of 8 weeks Resistance Training on BDNF and TrkB in the Hippocampus of Adult Male Rats. Armaghane danesh. 2014; 19(5): 380-9.

22. Eslami R, Gharakhanlou R, Mowla J, Rajabi H, Mohammadkhani $\mathrm{R}$. Effect of resistance exercise on protein content and $m R N A$ expression of NT 4/5 in rat slow and fast muscles. Journal of Gorgan University of Medical Sciences. 2014; 16(1): 35-40.

23.Moghadasi M, Edalatmanesh M, Moeini A, Nematollahzadeh mahani M S, Arvin H. Effect of 8 weeks resistance training on plasma levels of nerve growth factor and interlukin-6 in female patients with multiple sclerosis. Iran South Med J. 2015; 18(3): 527537.

24.Kalinowska-Lyszczarz A, Losy J. The Role of Neurotrophins in Multiple Sclerosis-Pathological and Clinical Implications. International Journal of Molecular Sciences. 2012; 13: 13713-25. doi: 10.3390/ijms131013713. 
25.Ylä-Kotola TM, Kauhanen MSC, Asko-SeljavaaraSL. P75 Nerve Growth Factor Receptor Is Expressed in Regenerating Human Nerve Grafts. Journal of Surgical Research. 2008; 254-61. DOI:10.1016/j.jss.2007.05.028.

26.Moghani Ghoroghi F, Nobakht M, Esmaeilzade B, Bakhtiyari M, Hejazian LB. Effect of Neurotrophin-3 on differentiation of rat hair follicle stem cells into neural like cells. Journal of Iranian Anatomical Sciences. 2012; 9(37): 269-78.

27.Urshansky N, Mausner-Fainberg K, Auriel E, Regev $\mathrm{K}$, Farhum F, Karni A. Dysregulated neurotrophin mRNA production by immune cells of patients with relapsing remitting multiple sclerosis. Journal of the Neurological Sciences. 2010; 295: 31-7. doi: 10.1016/j.jns.2010.05.019.

28.Shayan A, Bagherzadeh F, shahbazi M, choobineh S. The Effect of Two Types of Exercise the (Endurance and Resistance) on Attention and Brain Derived Neurotropic Factor Levels in Sedentary Students. 2015; 6(4): 433-52.

29.GoÂmez-Pinilla F, Ying Z, Opazo P, Roy R.R, Edgerton R. Differential regulation by exercise of BDNF and NT-3 in rat spinal cord and skeletal muscle. EuropeanJournalofNeuroscience. 2001; 13: 1078-84.

30.Ying Z, Roy RR, Edgerton R, Gomez- Pinilla F. Voluntary exercise increases neurotrophin-3 and its receptor TrkC in spinal cord. Brain Research. 2003; 987(1): 93-9.

31.Eslami S, Hakimi M, Ali-Mohammadi M, Karimiyani N. Comparing the effects of hydrotherapy, relaxation and McKenzie exercise on improvement of chronic low back pain in athletes. Journal of Anesthesiology and Pain official (JAP). 2014; 4(2): 11-21.
32. Masoodi Nejad M, Khosroo E, Shirvani H. Effect of combined training on strrngh muscle and functional capacity in women with multiple sclerosis. Journal sport physiology (research on sport science). 2013; 4(16): 8196.

33. Sami S, Hakimi M, Ali-Mohammadi M, Karimiyani N. Comparing the effects of hydrotherapy, relaxation and McKenzie exercise on improvement of chronic low back pain in athletes. Journal of Anesthesiology and Pain official (JAP). 2014; 4(2): 11-21.

34.Shahnazari Z, Marandi S M, Shayegan Nejad V. The Effect of Pilates Exercises and Aquatic Trainning on Walking Speed in Women with Multiple Sclerosis. jgbfnm. 2013; 10(2): 10-17.

35. Yousefvand Z, Parnow A, Ahsan B, Fayazi B. Effect of 8-week resistance training on muscle strength and functional capacity in women with multiple sclerosis $(M S)$. Journal of Sport in Biomotor Sciences. 2012; 6(2): 71-82.

36.Funakoshi H, Belluardo N, Arenas E, Yamamoto Y, Casabona A, Persson $\mathrm{H}$, et al. Muscle derived neurotrophin-4 as an activity-dependent trophic signal for adult motor neurons. Science 1995; 268 (5216):14959.

37.Walker UA, Schon EA. Neurotrophin-4 is upregulated in ragged-red fibers associated with pathogenic mitochondrial DNA mutations. Ann Neurol. 1998; 43(4): 536-540. 